\title{
Interfaces dos saberes ambientais: complexidade e educação política difusa
}

\section{Interfaces of environmental knowledge: complexity and diffuse policy education}

Antonio Teixeira de Barros - Doutor em Sociologia pela Universidade de Brasília. Pós-doutor em Comunicação pela Universidade Fernando Pessoa. Docente e pesquisador do Programa de Mestrado em Ciência Política do Centro de Formação da Câmara dos Deputados (CEFOR). E-mail: antonibarros@gmail.com

\section{Resumo}

Analisa as interfaces dos saberes ecológicos com a educação ambiental e política, ambas entendidas como educação difusa, que se realiza no âmbito das relações sociais e educativas do cotidiano, relevantes do ponto de vista da conversação civil e da cidadania. Ressalta a visão de interdisciplina e complexidade do ambientalismo e sua dimensão educativa e política. Tanto a educação como o ambientalismo constituem campos convergentes na dimensão de (re) construção e (re)produção simbólica da realidade e de suas estruturas políticas. Além disso, a educação ambiental é entendida como instrumento para formar cidadãos para atuarem na sociedade, assumindo a responsabilidade pelo ambiente natural, a cultura local e o meio social.

\section{Palavras-chave}

Educação, Sociedade e Cultura. Educação Ambiental Difusa. Complexidade Sociocultural e Educativa. Educação Ambiental e Educação Política.

\begin{abstract}
This paper analyzes the ecological knowledge interfaces with environmental education and politics, both understood as diffuse education which takes place in the context of social and educational relations of everyday life and it is relevant from the point of view of civil conversation and citizenship. Emphasizes the vision of interdiscipline and complexity of environmentalism and its educational and political dimension. Both education as environmentalism are convergent fields in the dimension of (re)construction and (re)production symbolic of reality and their political structures. In addition, environmental education is understood as a tool to educate citizens to act in society, assuming responsibility for the natural environment, local culture and the social environment.
\end{abstract}

\section{Keywords}

Education, Society and Culture. Diffuse Environmental Education. Educational and Sociocultural Complexity. Environmental Education and Political Education. 


\section{INTRODUÇÃO}

O ambientalismo reúne, desde suas pioneiras e tímidas manifestações, nas primeiras décadas do século XX, conhecimentos e referências dos mais diversos campos do conhecimento, tanto das ciências naturais como das sociais, todos com interface com a educação, especialmente a educação política em sua dimensão difusa. Iniciado como movimentos de defesa, proteção e conservação do meio natural, vinculado, portanto a saberes específicos desse campo, com o passar do tempo adquiriu projeção política e tornou-se um dos desafios para a educação, em sua dimensão de formação de mentalidades para a atuação consciente de cidadãos no mundo globalizado.

Diante do posto, discute-se neste texto a hipótese de que a educação ambiental, da forma como é entendida hoje, é tributária de um ideário político gestado pelos diferentes movimentos ambientalistas em sua dimensão convergente de transformação social, econômica, cultural e política das sociedades contemporâneas. Assim, parece coerente argumentar que a educação ambiental especializada e institucionalizada, tão em voga atualmente, foi precedida por uma visão anterior que integrava os ideários ecológicos ancorados nas ideologias de transformação das estruturas sociais e políticas. Assim, pode-se afirmar que o ambientalismo trouxe consigo uma concepção de educação política difusa, a qual serviu de base para a posterior definição de ideias para a educação ambiental em suas diversas interfaces, inclusive com a educação política em sentido estrito, uma vez que a consciência ambiental requer que o cidadão também esteja ciente de seus direitos, de seus deveres e do seu papel como agente político de transformação da sociedade. No contexto atual, portanto, talvez o mais adequado seja afirmar que a educação política e a educação ambiental fazem parte da mesma lógica, assumindo a dimensão de um binômio ontológico e epistêmico, integrando o ser e o conhecimento de si, da natureza e da sociedade.

O pressuposto que norteia o estudo é o de que os discursos sociais sobre ambiente e sobre educação política e ambiental não devem ser entendidos como produção autônoma, uma vez que se reportam às concepções aos e saberes produzidos por diversos atores sociais, políticos, culturais e educacionais (instituições estatais, partidos políticos, entidades científicas, universidades, movimentos sociais e ambientalistas). Além da diversidade de atores, o debate público no plano educacional e político passou a incorporar diferentes fatores relacionados aos temas ambientais (fatores naturais, políticos, econômicos, culturais, ideológicos). Trata-se, portanto, de um discurso condicionado por 
múltiplos fatores, atores sociais, culturais, educacionais e políticos em suas diversas configurações de relações e interações.

Entendendo que a educação deriva da inserção em relações sociais multifuncionais (PETITAT, 2011) é que se justifica tal enfoque, assentado da hipótese de que o desenvolvimento do ambientalismo implica sua inserção no campo dessas relações, implicadas no conceito de educação difusa, ou seja, práticas educativas em sua dimensão mais ampla (além do contexto escolar) que envolve atividades sociais, culturais e políticas "orientadas à transmissão de comportamentos, disposições, crenças e competências" (PETITAT, 2011, p.366). Isso envolve uma concepção de educação integrada às relações e atividades do cotidiano, isto é, as relações educativas não especializadas e não regulamentadas, inseridas nas novas dinâmicas de socialização e aprendizagem da chamada "modernidade líquida" (BAUMAN, 2001).

$\mathrm{O}$ argumento desenvolvido ao longo do texto problematiza como as concepções supracitadas se aplicam ao ambientalismo, no âmbito da discussão sobre como se deu a inserção dos saberes ecológicos no âmbito da educação, a partir de duas perspectivas específicas, as quais são articuladas no escopo analítico do texto: a educação ambiental e a educação política difusas. A escolha dessas duas perspectivas se justifica pela afinidade de ambas com a abordagem da educação difusa, tão em voga atualmente, sob o prisma sociológico do estudo das relações sociais no âmbito da educação.

O texto está organizado em três partes que se complementam, segundo a progressão das ideias desenvolvidas no escopo analítico. A primeira apresenta um panorama da evolução histórica da relação entre os saberes ambientais e o contexto da educação, entendendo tal contexto como o solo epistemológico para a emergência da educação política difusa expressa pelas ideias ecológicas. A segunda enfatiza a dimensão política do ambientalismo como consequência do processo de racionalização cultural e ampliação dos espaços de educação em sua dimensão difusa. A terceira contextualiza o debate sobre a evolução do pensamento ambiental na perspectiva de integração com outros saberes, na vertente denominada pensamento complexo.

\section{A INSERÇÃO DO AMBIENTALISMO NA PERSPECTIVA DA EDUCAÇÃO}

A construção das interfaces dos saberes ambientais com a educação, em nível internacional, começou a ser modelada em decorrência das discussões sobre as consequências da I Guerra Mundial, especialmente devido ao uso de 
substâncias químicas. Esse olhar já se caracterizou como a visão de especialistas de áreas distintas de conhecimento, com ampla repercussão entre educadores, o que já mostrava a tendência de formação de uma interdisciplina social de natureza complexa. Assuntos diretamente relacionados com a educação ambiental, como proteção da fauna e da flora, poluição, desenvolvimento sustentável, gestão de resíduos sólidos e aquecimento global passaram a requerer explicações de diversas áreas científicas e passaram a ser incluídos também no debate político. Foi dessa constatação que surgiu a ideia de analisarmos o ambientalismo como interdisciplina e sua relação com a educação, devido à complexidade contida nessa abordagem, na perspectiva de autores como Edgar Morin (2002) e Enrique Leff (2002).

A crise ambiental afeta também a razão, o pensamento social, o conhecimento político, as práticas culturais e o comportamento humano, moldado pela educação. A relevância para a abordagem sociológica se deve ao fato de que a própria sociologia como ciência "é uma filha das crises sociais do século 19 e inicio do século 20" (SOEFFNER, 2009, p. 324). Isso explica, inclusive, as afinidades entre ambientalismo, sociologia e educação, três áreas que exercem papel-chave nos contextos de crise social, no sentido de problematização da realidade e de reinvenção de ideias e valores. Afinal, como argumenta Hannah Arendt, "em toda crise é destruída uma parte do mundo, alguma coisa comum a todos nós" (2000, p. 227), ideia se aplica diretamente ao foco da discussão aqui proposta.

Essa crise requer uma contextualização mais detalhada sobre sua evolução e redefinições, no que se refere especificamente ao escopo da análise deste artigo. Um dado contextual relevante diz respeito ao fato de que nas primeiras décadas do século XX, a ecologia ${ }^{1}$ era tratada de forma episódica e fragmentada tanto pela escola como pelos meios de comunicação e a sociedade em termos gerais. Mas com o passar do tempo, tornou-se um supertema da agenda social e educacional, especialmente após os anos de 1970, ao romper a lógica de assunto eventual da agenda pública para tornar-se problemática sociopolítica educacional com abordagem continuada, complexa e recorrente (BARROS; SOUSA, 2010). Assim, o ambientalismo passou de um espaço ermo em termos de conhecimento a um campo fértil, sincrético e híbrido de novas epistemologias e saberes.

Atualmente, os debates sobre ambiente abrangem assuntos diretamente relacionados com a educação política e ambiental e com o cotidiano do cidadão,

1 Cabe esclarecer que o termo inicial utilizado para se referir ao pensamento verde era "ecologia". Contudo, com o passar do tempo, passou-se a preferir "ambientalismo". Conforme Pádua (1986), o sentido do primeiro situava-se mais no campo do meio natural, enquanto o segundo passou a englobar a cultura e a sociedade. Em suma, no primeiro caso havia certa conotação de externalidade (mundo exterior), enquanto o segundo inclui o homem, a cultura, a sociedade. É nesta acepção que os dois conceitos são utilizados neste trabalho. 
como a coleta seletiva de lixo, o desperdício de água, a redução do consumo de energia elétrica nos domicílios, o uso de combustíveis fósseis nos automóveis etc. Contudo, essa abordagem é recente, o que justifica a necessidade de se analisar como se deu a evolução dessa temática e como os assuntos enfocados sob a ótica de uma perspectiva única de conhecimento foram adquirindo nuances de interdisciplina e de pensamento complexo, na perspectiva da educação ambiental.

Do ponto de vista histórico, o pensamento ambiental recebeu interferências diretas da agenda global, em função do contexto político e da atuação de organismos internacionais (ONU e Clube de Roma) das organizações não-governamentais, das universidades e dos partidos políticos (BARROS; SOUSA, 2010). Esses organismos internacionais e entidades sociais, desde o início, enfatizavam o aspecto educativo da temática, mesmo que não fosse do ponto de vista da educação formal. Em termos específicos, no plano da concertação política entre as nações, a Carta de Belgrado (1975) é considerada um marco na educação ambiental, com recomendações sobre a necessidade de ações educativas permanentes e continuadas para a formação cidadã no âmbito ambiental. A Conferência Intergovernamental sobre Educação Ambiental realizada em Tsibilisi (EUA), em 1977, constitui outro marco na discussão sobre a necessidade de produção de conhecimentos interdisciplinares, conforme os princípios da complexidade epistemológica. A Conferência Internacional de Tessalônica, na Grécia (1997) teve como tema "Educação e Conscientização Pública para a Sustentabilidade" e enfatizou a articulação de ideias relacionadas com sustentabilidade, educação, ética, cidadania, identidade, diversidade cultural e participação social. Em 2005 teve início a década da educação para o desenvolvimento sustentável (2005-2014), instituída pela Unesco, com o objetivo de implementar os projetos apresentados pela Agenda 21.

Diante do exposto entendendo a educação como requisito para a ação política e como mecanismo de transformação social (VARGAS, 2005; JACOBI, 2003; MOTA JÚNIOR, 2009), é que nos propusemos a analisar a educação ambiental na perspectiva política, uma vez que tanto a educação como o ambientalismo constituem campos convergentes na dimensão de construção e reprodução simbólica da realidade e de suas estruturas políticas, no sentido abrangente do termo. Além disso, a educação ambiental é entendida como instrumento de formação para a cidadania, ou seja, no sentido de formar cidadãos para atuarem na sociedade, assumindo, inclusive, a responsabilidade pelo ambiente natural, a cultura local e o meio em que vivem (CARVALHO, 1992; JACOBI, 2003; VARGAS, 2005). 
Nessa perspectiva a escola deve participar e atuar "como uma instituição dinâmica, com capacidade de compreender e articular os processos cognitivos com os contextos da vida" (JACOBI, 2003, p. 197). Mesmo assim, não basta a educação ambiental formal como disciplina curricular, mas inserida na cultura e na formação continuada, o que requer a integração de saberes e a mudança de valores. Afinal, a educação ambiental deve buscar a solidariedade, a igualdade e o respeito à diferença através de formas democráticas de atuação baseadas em práticas dialógicas. "Isso se consubstancia no objetivo de criar novas atitudes e comportamentos diante do consumo na nossa sociedade e de estimular a mudança de valores individuais e coletivos" (JACOBI, 2003, p. 197).

Uma educação ambiental que consiga atender a esse amplo escopo de atuação deve ser transversal, complexa e configurar-se como interdisciplina sociocultural e política. Isso implica, além da configuração epistêmica de interdisciplina, uma revolução endógena nas disciplinas relacionadas, atingindo também redefinições no nível de intradisciplina. Tal argumento se justifica porque a relação entre as disciplinas que envolvem conteúdos ecológicos não deve ser entendida somente no plano exógeno ou das externalidades. Tal lógica de epistemologias de integração também afeta a configuração interna de cada disciplina, provocando revisões no interior de cada uma delas. Essas revisões, em alguns casos, podem produzir efeitos mais vigorosos do ponto de vista da eficácia simbólica da ação educativa do que aquelas operadas no plano externo.

Diante desse multifacetado quadro de referência é que o ambientalismo passou a ser tomado como exemplo paradigmático da perspectiva de ampliação do olhar sociológico sobre a educação, principalmente pelo seu potencial de integrar saberes e epistemologias (no plano exógeno e endógeno das disciplinas), além de permitir problematizações complexas e transversais sobre a realidade social e política. Como resultado disso, além do campo da educação ambiental formal, inserida nas relações escolares propriamente ditas, as reflexões sobre ambientalismo foram incorporadas pelas demais configurações sociais, chegando ao nível da conversação civil, talvez uma das manifestações mais emblemáticas do potencial desse campo de saberes como educação política difusa.

A conversação civil (ECO, 2010) inclui os debates informais protagonizados pelos próprios cidadãos, sem interferência ou tutela do Estado ou de instituições e instâncias reguladoras das relações sociais e políticas. Trata-se, portanto, de práticas situadas no campo da educação difusa no seu sentido amplo. Tais práticas são derivadas da inserção dos indivíduos em relações sociais multifuncionais, a exemplo de discussões na esfera pública virtual e participações voluntárias em fóruns sociais, associações comunitárias, programas de rádio e televisão, por 
exemplo. No caso do ambientalismo, as conferências e fóruns internacionais mencionados anteriormente em muito contribuíram para o desenvolvimento da cultura da conversação civil como prática de educação política difusa.

Somado a isso se deve destacar a vocação criativa e recriativa da educação e suas práticas, na perspectiva reinvenção não só das dinâmicas educativas em si, mas também de renovação do mundo, como salienta Hannah Arendt em seu célebre livro Entre o passado e o futuro (2000). A educação cria e recria o mundo no sentido de que se constitui o elo entre o conhecimento produzido pela humanidade no passado e o potencial de saberes das novas gerações que ingressam na escola. Além disso, uma das finalidades da educação é a racionalização cultural, no sentido weberiano, ou seja, de oferecer aportes heurísticos, éticos e críticos para a interpretação da vida social. Tudo isso pode ser resumido na ideia de Petitat (2011) de que educação, cultura, invenção e reinvenção do mundo são indissociáveis, ou seja, "a educação participa diretamente da produção e da difusão do novo". Um exemplo disso são os debates e ideias inovadoras que emergiram com o ambientalismo, em sua dimensão de educação ambiental a partir da análise dos documentos produzidos pelas conferências internacionais mencionadas acima. Além disso, destaca-se a dimensão de educação política difusa, expressa no conceito de conversação civil. Passemos ao aprofundamento da dimensão política do ambientalismo, sua vertente mais vigorosa antes da abertura para o pluralismo expresso pelas retóricas conciliadoras do desenvolvimento sustentável, ou seja, a passagem do ambientalismo monossetorial para o plurissetorial.

\section{REDEFINIÇÕES POLÍTICAS DO AMBIENTALISMO: DO RADICA- LISMO À RACIONALIZAÇÃO E INTEGRAÇÃO DE SABERES}

Para a análise das redefinições e revisões políticas do ambientalismo, em sua trajetória nas últimas décadas, optamos pela perspectiva da sociologia compreensiva de Max Weber, que procura a interpretação das ações individuais a partir do sentido atribuído pelo agente social. No caso do ambientalismo isso implica avaliar a atuação social, política e educativa dos principais atores envolvidos na causa verde e os sentidos e identidades por eles construídos. Em termos mais específicos, tal opção se justifica pela inclusão da educação no escopo da análise weberiana sobre o processo de racionalização cultural do Ocidente, à luz do qual o ambientalismo deve ser compreendido. Em outras palavras, na abordagem weberiana, a educação é vista como parte do projeto amplo de racionalização das sociedades ocidentais, contribuindo para a secularização e o "desencantamento" do mundo social. 
Racionalismo para Weber é um conceito supranacional (SOUSA, 1999), assim como o ambientalismo planetário e multissetorial (racionalismo como tipo ideal). Apesar de não ter apresentado um conceito fechado de racionalização, Weber utiliza o termo em vários de seus escritos, especialmente em Economia e sociedade (1999), com o propósito de caracterizar o processo que impulsionou o desenvolvimento ocidental e uma das formas específicas de dominação legítima. Portanto, trata-se de um conceito considerado central para a compreensão de seu pensamento, além de um instrumento essencial "para se entender o desenvolvimento social, o progresso técnico das sociedades, bem como o projeto de modernidade no qual nos inserimos" (CARDOSO, 2008, p. 257). A importância do conceito reflete-se nas formulações de Weber sobre o potencial civilizador da racionalização, seja na economia, na ciência, na educação, na cultura e na política. Em sua dimensão intelectual, diretamente associada à educação, a racionalização é vista por Weber como indutora do processo civilizatório.

As reflexões de Weber sobre racionalização se complementam com a tese da secularização e desencantamento do mundo, formando uma tríade (racionalização, secularização, desencantamento) que resulta do afastamento do mundo social do universo das crenças religiosas, ou seja, do mundo encantado pelas explicações mágicas sobre a natureza e as relações humanas e sociais (PIERUCCI, 2000). À medida que avançam os processos de racionalização social por meio da ciência, da técnica, das normas jurídicas e das formas de dominação e poder, as sociedades ocidentais se afastam do mundo das explicações sobrenaturais e das relações baseadas em narrativas mitológicas e místicas. Assim, o mundo desencantado é aquele que "prescinde das escolhas e da intervenção criadora da agência social, motivada por impulsos exógenos aqueles contidos e gerados no e pelo mecanismo burocrático-administrativo que, tecnicamente, perpetua a ordem sociopolítica" (SOARES, 2000, p. 343).

A tríade supramencionada é consequência do papel que a educação passou a exercer como formadora de valores e modeladora de comportamentos sociais, suplantando a religião. Se antes as igrejas é que formavam as consciências, com o processo de secularização, as escolas é que passaram a atuar na orientação de valores e na formação da personalidade e na "desmagificação" do mundo. Os sistemas educacionais foram fundamentais na construção do projeto de modernidade cultural e essa "modernidade desencantada" é fundada no princípio da subjetividade, pois "a transição para a modernidade é um processo de internalização e de subjetivação, no qual o caminho para dentro tanto mais demora, quanto mais leva para nós mesmos - e não mais para cima, para deus" (SCHLUTCHER, 2000a, p. 18). Afinal, ao contrário da religião, o pensamento 
racional não responde de forma objetiva e imperativa o que devemos fazer e como devemos viver. É pela educação que o sujeito moderno adquire as ferramentas intelectuais e cognitivas para sua ação no mundo.

A educação, na concepção de Weber, representa a dimensão cultural do processo de racionalização ocidental, "uma vez que os fenômenos intelectuais mais significativos da história moderna foram a desilusão, a intelectualização e a racionalização do mundo", a ciência e educação afetam diretamente o significado do mundo moderno (SCHLUTCHER, 2000b, p. 60). Isso porque o conhecimento científico, ao espalhar a crença de que em princípio é possível dominar todas as coisas por meio do cálculo, quebrou o monopólio das religiões de redenção de atribuir esse significado à crença que propagam. Essa reflexão reforça a tese de que o discurso de Weber sobre o papel da ciência e sua relação com a política deixa implícito que se "trata também de um discurso sobre a educação política", uma vez que Weber defendia a autonomia das universidades para que elas não se tornassem igrejas, nem seitas, nem instituições de apoio direto ao Estado" (SCHLUTCHER, 2000b, p. 80; p. 96). Esse processo possibilitou que a educação se tornasse protagonista de narrativas sociais desvinculadas do pensamento mágico, o que nos levou à elaboração de uma prosa do mundo ${ }^{2}$ renovada e ancorada em bases racionais. Cabe reforçar que o próprio conceito de progresso, intrinsecamente associado à modernidade, decorre da própria noção de desencantamento do mundo e da consequente secularização. Percebese ainda que a educação política constitui o solo epistemológico das ideias de Weber quando ele afirma que "somos seres culturais, dotados da capacidade e da vontade de tomar atitudes ponderadas com relação ao mundo e dar-lhe significado", como observa Schlutcher (2000b, p. 63).

Para Weber a moralidade ocidental na perspectiva de necessidade de compreensão do mundo nasceu como movimentos endógenos à racionalização religiosa. Dessa forma, o ambientalismo apresenta algumas similaridades que se aproximam da moralidade e do conhecimento próprio do campo religioso, calcadas em valores como solidariedade, coletividade e comunitarismo. Por outro lado, o ambientalismo prega um discurso ascético, mas desvinculado de religião (ética intramundana) baseada nas formas pós-tradicionais de solidariedade social. Trata-se de elementos similares ao campo religioso, porém ancorados em uma moralidade secular e uma racionalidade de intregração de saberes. A educação, por sua vez, é vista como instrumento de libertação do jardim mágico das teodiceias religiosas que moldavam eticamente o mundo. Na modernidade a escola é que

2 Expressão utilizada por Michel Foucault em As palavras e as coisas para designar a construção de narrativas e epistémes sobre a vida social e a cultura. 
exerce tal função. Nessa perspectiva, a educação ambiental é fundamental como categoria heurística, pois a educação é abraçada pela concepção de Weber, mas livre da epistemologia que opunha ciência e religião, o que, no contexto atual, pode-se entender como conhecimento científico e saberes tradicionais sobre ecologia. Trata-se de uma concepção plural que engloba a lógica de interdisciplina e de pensamento complexo, como será abordado na sequência.

\section{OAMBIENTALISMO COMO INTERDISCIPLINAE PENSAMENTO COMPLEXO}

Desde que a Ecologia foi reconhecida como uma ciência, a partir das contribuições do cientista alemão Ernst Haeckel, publicadas em 1869, passou a ser entendida e aceita como a ciência das relações entre os seres vivos e seu meio, concentrando-se principalmente no estudo de problemas locais, circunscritos a ecossistemas específicos, com pouca importância às diversas interações com a vida social. Posteriormente, passou-se a falar em ciências ambientais, as quais necessitariam integrar-se para formar uma ciência da biosfera, entendendo-se esta como algo mais abrangente, voltada para a globalidade da questão ecológica e sua interface com a educação, a cultura e a política. Mas, "que gênero de ciência pode explicar os vínculos complexos entre a vida e seu meio, em escala planetária?" (BOTKIN, 1992).

No âmbito das Ciências Sociais, postula-se que o ambientalismo constitui um novo quadro de referência, que contempla a dimensão política e educacional. Afinal, trata-se de um movimento que além de multidisciplinar é planetário (VIEIRA, 1995). É neste sentido que o ambientalismo passou a ser entendido como uma interdisciplina, ou seja, uma área de conhecimentos que se relaciona com diversos outros campos de saberes e com práticas educacionais, políticas e culturais.

Como já foi salientado anteriormente, durante a primeira metade do século $\mathrm{XX}$, o discurso ecológico esteve separado do pensamento político, econômico e social. Com a intensificação do debate sobre o tema passou-se a postular que o discurso ecológico é essencialmente político. Antes de se reduzir a questão a argumentos técnicos para a tomada de decisões racionais, há que se negociar alianças entre os distintos grupos sociais capazes de impulsionar as transformações necessárias. Nessa trajetória de afirmação política do ambientalismo, os estudos no âmbito das Ciências Sociais foram imprescindíveis para ampliar a própria concepção de ecologia e sua interface com a educação. Guatari (1993) referese à existência de três ecologias: a do ambiente, a das relações sociais e a da 
subjetividade humana, todas sob a égide ético-estética da ecosofia social, sendo que esta ecosofia consiste em desenvolver práticas específicas que tendem a modificar e a reinventar modos de ser e estilos de viver, seja no âmbito familiar, do contexto urbano, do trabalho, do lazer, da escola e do pensamento político.

Nessa ordem de ideias, as transformações contínuas na esfera privada e na esfera pública promovem uma relação da subjetividade humana com sua exterioridade, seja ela social, animal, vegetal ou cósmica, "que se encontra assim comprometida numa espécie de movimento geral de implosão e infantilização regressiva" (GUATARI, 1993, p.8). As formações políticas e as instâncias executivas parecem totalmente incapazes de apreender essa problemática no conjunto de suas implicações, pois se concentram na perspectiva tecnocrática, já que a abordagem limita-se ao campo dos danos industriais, "ao passo que só uma articulação ético-política - a que chamo ecosofia - entre três registros ecológicos (o do meio ambiente, o das relações sociais e o da subjetividade humana) é que poderia esclarecer convenientemente tais questões" (GUATARI, 1993, p. 8).

Por essas razões, defende o autor citado, em sintonia com o escopo analítico de Morin (1991b) que a natureza não deve ser separada da cultura e precisamos aprender a pensar 'transversalmente' as interações entre ecossistemas, mecanosfera (tudo o que compõe a vida orgânica) e universo de referências sociais e individuais, na perspectiva de um pensamento social e cultural complexo. Isso porque o chamado capitalismo pós-industrial ou capitalismo mundial integrado tende, cada vez mais, a descentrar seus focos de atenção das estruturas de produção de bens e de serviços para as estruturas produtoras de signos, de sintaxe e de subjetividade, por intermédio, especialmente, do controle que exerce sobre a educação.

Morin chama a atenção ainda para o fato de que a compreensão social da ecologia ${ }^{3}$ requer uma consciência que exige policompetências; a visibilidade que o tema adquiriu nos mostra que, ao contrário do dogma da hiper-especialização, há um conhecimento organizacional global que só ele é capaz de articular as competências especializadas para compreender as realidades complexas. A Ecologia é entendida por Morin como uma ciência aberta, que está tentando produzir uma síntese pluridisciplinar, destacando-se a contribuição de cientistas naturais e sociais de diversos campos, além de educadores e filósofos. Assim, o pensamento ecológico passou a exercer o papel de protagonista e articulador de saberes de natureza multi e interdisciplinar. Isso porque a Ecologia tem como objeto de estudo as interações entre todas as espécies de seres vivos, com o

Edgard Morin prefere o termo "ecologia" no lugar de "ambiente", por entender que expressa com mais nitidez a complexidade e a natureza de interdisciplina (MORIN, 1973; 1991a; 1991b). 
seu habitat e com o meio social, ocupando-se ainda do estudo da racionalidade (logos) desse complexo domínio sócio-ambiental. As ideias ecológicas passaram a exercer papel fundamental na valorização de outras formas de conhecimento, sobretudo os saberes empíricos, resultantes das práticas e vivências do cotidiano, diretamente relacionado com a sobrevivência do gênero humano, como é o caso do debate social recente sobre poluição e aquecimento global, por exemplo. Afinal,

O diálogo de saberes se produz no encontro de identidades. É a entrada do ser constituído por intermédio de sua história até o inédito e o impensado, até uma utopia arraigada no ser e no real, construída a partir dos potenciais da natureza e dos sentidos da cultura. $O$ ser, para além de sua condição existencial geral e genérica, penetra o sentido das identidades coletivas que constituem o crisol da diversidade cultural em uma política da diferença, mobilizando os atores sociais para a construção de estratégias alternativas de reapropriação da natureza em um campo conflitivo de poder, do qual se desdobram sentidos diferenciados e, muitas vezes, antagônicos, na construção de um futuro sustentável (LEFF, 2009, p.19).

Como se observa no trecho supracitado, trata-se do engendramento de uma nova concepção simbólica e cultural, calcada em valores e sentidos nãoimediatistas; alguns até contrários à moderna ideologia econômica (capitalista) e ao individualismo. Embora não possamos ignorar que "não se pode entender a notável expansão do ecologismo fora da reciclagem em curso do capitalismo mundial [...]. O próprio estímulo ao aumento do consumo individual enfrenta sérios problemas de economias de escala nos países desenvolvidos" (BENJAMIN, 1993, p. 151). Ademais, a proteção ambiental "está se tornando a principal área de investimentos para um sistema ávido por alternativas de reciclagem e esperto demais para perder oportunidades que combinem negócios e ideologia vendáveis no mundo inteiro” (p. 152). É necessário ressaltar, portanto, que seu caráter de amálgama de vários saberes e culturas, abriu caminhos plurais para o desenvolvimento de ideias inovadoras e para a gestação de novas formas de organização dos movimentos ambientalistas, como veremos a seguir.

\subsection{DA INTERDISCIPLINA À COMPLEXIDADE}

As redefinições e reconfigurações do ambientalismo que conduziram à sua constituição como interdisciplina devem ser analisadas como essenciais para as mudanças de rumo que resultariam no pensamento social e político, nas práticas ambientalistas e nas ideias educacionais voltadas a formação da consciência cidadã. A difusão das ideias sobre pensamento complexo, a partir das 
contribuições de Edgar Morin, também deve ser considerada, uma vez que essa visão se fundamenta em uma perspectiva interdisciplinar e multirreferenciada sobre os sistemas sociais, a cultura, as identidades, a educação e a natureza, resultando em um "tecido de constituintes heterogêneos inseparavelmente associados" (MORIN, 1994). Assim, o principal argumento para considerar o ambientalismo como pensamento complexo é o fato de que o mesmo rompe com a dicotomia indivíduo x sociedade. Segundo Morin (1973), a complexidade, neste caso, deve-se, sobretudo à inclusão de outros elementos, o que resulta no seguinte esquema: espécie à indivíduo à sociedade à cultura à natureza.

Para o autor citado, existe um "ambi-sistema" bio-social e cultural que se insere em um "ambi-sistema” sócio-individual. Em outras palavras, a questão ecológicoambiental não apresenta apenas aspectos biológicos, nem apenas sociais, mas um conjunto de fatores, que forma um sistema complexo e contraditório de elementos biológicos, humanos, coletivos, individuais, culturais, simbólicos e econômicos. Aqueles que parecem puramente naturais (quando assim o são tomados) se contradizem com aqueles cujos aspectos sociais e culturais são ressaltados. Esses, por sua vez, estabelecem uma relação contraditória quando se pensa, por exemplo, nos aspectos econômicos. Enfim, é possível desenvolver uma rede de contradições entre esses fatores, dependendo do enfoque analítico. $\mathrm{O}$ pensamento de Morin tenta relacionar todos eles, sem construir uma hierarquia padrão.

O pensamento ecológico, portanto, surge como resultado de uma "aliança" entre política, ciência, cultura e educação, no contexto científico pós-moderno. A valorização da área de ciência, tecnologia e inovação é apontada como exemplo, uma vez que esse trinômio confirma a lei do progresso irreversível (MORIN et al., 1991b). Fenômeno esse que se enquadra na concepção moderna do avanço científico, fundado no princípio da ciência materialista, da razão leiga, da educação formal e da evolução histórica. Assim, tem uma nova arena de conhecimento (o conhecimento científico-tecnológico) que não reivindica mais a "pureza" científica tradicional. Ao contrário, esse novo campo de conhecimento aglutina e justapõe saberes de diversos outros campos, tanto teóricos como normativos e práticos.

O pensamento complexo "propõe o abandono do paradigma triunfalista de controle do real. Em seu lugar, o reconhecimento da irredutiblidade da incerteza, dos princípios da incompletude do saber e da biodegradabilidade das verdades científicas" (STROH, 1998, p. 44). As flutuações conceituais, as contradições, ambiguidades identitárias e oposições entre correntes de opinião, no âmbito do pensamento complexo, são consideradas elementos positivos, uma vez que o mesmo é movido por uma tensão permanente entre a aspiração a um saber não fragmentado e o reconhecimento da força das incertezas, 
ambiguidades e processualidades (dimensão inacabada) do conhecimento e da educação continuada.

Esse raciocínio está incluído na mesma visão de Edgar Morin (1994), para quem a complexidade é entendida como a ciência da organização dos contrários, ou seja, uma forma paradoxal de pensar a realidade e ainda um modo de tecer os fatos científicos com base não mais em dualidades, mas em paradoxos, pois a complexidade é o tecido organizador de eventos, ações, interações, retroações, determinações, acasos, que constituem o mundo fenomênico e se apresenta com os traços inquietantes do inextricável, da desordem, da incerteza, do imprevisível.

Nessa ordem de ideias, entende-se, pois a complexidade como a organização de aspectos, fatores e elementos identitários complementares, que, ao mesmo tempo, constituem opostos, ou seja, unidades que se opõem, mas que fazem parte de um mesmo sistema. Isto significa que as partes antagônicas e concorrenciais contribuem de forma positiva na organização de um sistema complexo, pois, "a complexidade reside na interrogação que podemos fazer quanto às condições, modalidades, limites e problemas colocados pelas complementaridades antagônicas e concorrenciais que organizam um sistema de investigação" (STROH, 1998, p. 47). O caráter relacional é a essência da complexidade. Segundo Morin (1994), todo sistema é fundamentado na sua substância relacional de pensamento, a exemplo da emergência do ambientalismo multissetorial brasileiro. Morin procura na complexidade cultural da sociedade contemporânea as explicações para a emergência de um pensamento ecológico, inclusive nos processos de rupturas, os quais, a seu ver, assumem o papel de "desvios inovadores", que criam as condições iniciais de uma transformação que pode eventualmente aprofundar-se - ou não.

Após a Conferência das Nações Unidas no Rio em 1992, houve uma ampliação da participação da sociedade civil em todo o mundo - o que também ocorreu no Brasil - com a emergência de novos atores sociais do ambiente, em um contexto sócio-histórico de distintas bases produtivas e de diferentes eixos de transformações sociais. Conforme Figueiredo (1996, p. 120), é neste quadro de mudanças no cenário internacional, que o ambientalismo se constitui "como força política tanto no que diz respeito à constituição de um corpo específico de valores, como a definição e agregação de atores com ele envolvidos".

A diversificação dos atores sociais está diretamente relacionada com a complexificação do ambientalismo, numa perspectiva agregadora, apesar das incompatibilidades existentes, das disputas de interesses e por visibilidade. Essa rearticulação das forças ambientais trouxe vantagens, em função da ampliação dos agentes envolvidos, da visibilidade e da ampliação da consciência ecológica, entre 
outros fatores. Esse cenário polinucleado caracteriza-se pela predominância das retóricas conciliadoras, em prol do desenvolvimento sustentável, numa perspectiva de reconciliação da ecologia com a economia. Contudo, a institucionalização dessa perspectiva ambiental reprimiu as correntes mais revolucionárias, a exemplo das vertentes ancoradas no ecossocialismo ou ambientalismo libertário e radical. Por outro lado, a perda do idealismo dos movimentos de inspiração radical pode ter sido compensado com o pragmatismo das organizações não governamentais do ambiente mais empenhadas em alianças em prol do desenvolvimento sustentável do que no confronto ideológico com o Estado e o os setores empresariais.

Pensadores como Norberto Bobbio (1992) e Eric Hobsbawn (1995) chamam atenção para a relação do ambientalismo com uma rede de outros atores sociais. Para o primeiro autor, os movimentos em defesa da natureza não devem ser compreendidos como iniciativas isoladas e autônomas, mas como parte de um conjunto de movimentos em defesa dos direitos humanos, incluindo as liberdades individuais, os direitos políticos e sociais. O ambientalismo, na visão de Bobbio se insere no âmbito dos chamados direitos de terceira geração (direitos étnicos, de gênero, de imigrantes, qualidade de vida, ecológicos etc.), ou seja, o direito relativo à natureza, no qual os sujeitos não são entendidos como indivíduos, grupos sociais, categorias profissionais ou instituições sociais. Em sua avaliação, nesses direitos de terceira geração, o sujeito é a própria humanidade. Hobsbawn complementa que esses movimentos apontam para reivindicações que exigem mudanças em toda a estrutura da sociedade e apelam para a adesão generalizada das pessoas e não apenas de categorias específicas. Os direitos ambientais são associados às reivindicações, campanhas e manifestações públicas em prol da paz, da qualidade de vida, da diversidade cultural, da integração sociocultural, do bem-estar geral da humanidade, independentemente de sua raça, religião, gênero ou nacionalidade.

Conforme a análise de Scherer-Warren (1996, p. 144), é esse aspecto de capilaridade e amplitude do ambientalismo que o impulsionou para a formação de redes inter, trans e multinacionais, com a contribuição de mais um elemento que catalisou a lógica das redes, que foi a ampliação das possibilidades da comunicação eletrônica, especialmente com a internet. Como consequência dessa capilaridade, a autora chama atenção para um modo simbólico peculiar de agir na esfera pública, com a instituição de novos códigos "criados de acordo com a ideia de uma comunidade idealizada, de uma utopia do que seria um mundo ecologicamente melhor, para a realização de uma cidadania planetária" (SCHERER-WARREN, 1996, p. 144). 
A autora citada destaca ainda um conjunto de estratégias dos atores sociais que incluem o ambientalismo em seu campo de ação: (a) parcerias com o poder público e com organizações privadas; (b) pressões institucionais; (c) intervenção na opinião pública; (d) estímulo à vigília cidadã. Na prática, todas essas estratégias se combinam. A primeira tem como meta a adesão de representantes de instituições governamentais com poder de decisão e intervenção nas políticas públicas, como conselhos municipais e prefeituras. A segunda é voltada para a alteração ou proposição de normas, leis, acordos internacionais e agendamento de debates, conferências e fóruns deliberativos sobre o assunto. A terceira prioriza a realização de protestos, campanhas, manifestos e eventos diversificados, com o intuito de ampliar a visibilidade aos temas ambientais, segundo o enquadramento das organizações ambientalistas. A última tenta prolongar o resultado das anteriores, com a instrumentalização da ação política organizada por grupos menores, a fim de cobrar a aplicação e a efetividade de medidas políticas, legislativas ou de ações governamentais. Os movimentos verdes tentam transformar os cidadãos em "fiscais da natureza" e agentes cotidianos da educação ambiental.

Sob esse prisma, o movimento ambientalista é classificado como um movimento histórico e multissetorial, vinculado às origens da ecologia política no Brasil (PÁDUA, 1996). Essa perspectiva teórica baseia-se no pressuposto de aglutinação de diversas forças sociais ao longo do tempo, transformando o movimento ambientalista em causa multissetorial e complexa, que reúne não só os ecologistas no sentido estrito do termo, mas também outros movimentos sociais preocupados com a insustentabilidade socioambiental, o crescimento populacional e a ocupação desordenada do solo urbano, a geração de tecnologias ecologicamente eficientes, a geração de energias renováveis e o debate sobre hábitos de consumo menos degradantes (VIOLA; LEIS, 1995).

Nessa visão o ambientalismo é concebido como força transformadora da história e elemento essencial à constituição de uma nova identidade cultural, devido a seu potencial para provocar reflexão na sociedade e redefinição de valores, comportamentos e identidades. Um exemplo disso é o chamado ambientalismo multissetorial complexo, que teria rompido as barreiras ideológicas e a identidade radical e permitido a constituição de uma rede com a participação de diferentes atores sociais, como movimentos políticos, sociais, empresariais e científicos, além de agências governamentais ou internacionais. Essa rede é que teria gerado as condições sociais e culturais necessárias para a difusão ampla e transversal dos valores ambientalistas, tornando a ecologia um tema simbólico horizontal, ou seja, de interesse geral (VIOLA; LEIS, 1995). 
O trabalho de Viola e Leis é avaliado por Agripa Faria Alexandre (2000) como contribuição teórica que se destaca pelo potencial analítico e singular, com larga utilização de material empírico. Entretanto, Alexandre critica a interpretação do movimento ambientalista brasileiro como um movimento histó rico e multissetorial. Em contraposição, a pesquisadora apresenta a teoria do ambientalismo político, seletivo e diferencial, com ênfase para as disputas, divergências e conflitos identitários. Conforme sua análise, a teoria do multissetorialismo pressupõe, equivocadamente, harmonia entre os diferentes atores dos movimentos ambientais, como se fosse uma pluralidade simbólica convergente. $\mathrm{Na}$ avaliação de Alexandre, $a$ interpretação do movimento histórico e multissetorial, traçada por Eduardo Viola e Ricardo Leis não consegue explicar o desenvolvimento do movimento ambientalista. Sua hipótese consiste em demonstrar que existem mais conflitos do que convergências entre os diferentes segmentos dos movimentos ambientalistas. A autora exemplifica com as oposições entre os movimentos ecoconservacionistas e os ecopreservacionistas e os conflitos entre os ecocapitalistas e os ecossocialistas (ALEXANDRE, 2000).

Apesar das críticas, Eduardo Viola e Ricardo Leis reafirmam sua tese do multissetorialismo complexo em estudos posteriores, com ênfase para a lógica da cooperação entre os movimentos ambientalistas. $O$ argumento consiste na ressalva de que embora existam no ambientalismo forças associadas ao mercado e ao Estado, deve-se registrar como um dado sumamente sugestivo "a razoável convivência, ao longo do tempo, de todas suas diversas vertentes e a predominância da cooperação por cima do conflito" (LEIS, 1999, p. 140). Assim, segundo a lógica multissetorial, a concordância é inerente ao pensamento ecocêntrico. As várias vertentes e setores do ambientalismo têm entre eles uma concordância num plano profundo, que permite aos diversos atores ser cooperativos apesar de suas diferenças. Em suma, o ambientalismo multissetorial não exclui a possibilidade de conflitos e disputas, mas põe em relevo, em perspectiva histórica, a formação de multiconvergências.

\section{CONSIDERAÇÕES FINAIS}

A configuração de interdisciplina complexa do ambientalismo, em sua interface com a educação política difusa envolve diferentes atores como cientistas, órgãos governamentais e não-governamentais, militantes, pesquisadores e educadores, além das diversas manifestações de aprendizagem social, incluindo a conversação civil, o jornalismo ambiental, entre outros. Em suma, o debate é complexo, pois incorpora diversas perspectivas e se constitui como força simbólica, cultural, política e educacional, tanto no que diz respeito à constituição 
de um corpo específico de valores como na definição e agregação de atores, práticas e interações.

Trata-se de um campo polinucleado de saberes, no qual os principais agentes e suas identidades organizam-se em núcleos que atuam como matrizes geradoras e difusoras de valores que se traduzem em ideários, lógicas, modelos de intervenção e normas que orientam a criação de novas percepções e princípios éticos que passarão a orientar as condutas. A conjunção de diferentes atores justifica-se pelo fato de que o ambientalismo é portador de valores e interesses que se sobrepõem às diferenças de gênero, etnia, religião, classe social, nível de renda e de instrução, público e privado, e de nacionalidade ou região. Dispensa os elementos corporativos, partidários ou particularistas, pois sua lógica é aglutinadora e não sectária. Assim, ampliam-se as esferas sociais de aprendizagem difusa e suas dimensões educativas e de produção e reprodução simbólica.

É necessário considerar, no escopo dos estudos sobre o tema, o potencial do ambientalismo como novo quadro social de referência para a educação e de renovação dos espaços de conhecimento que passarão a balizar os campos de alianças e negociações de sentidos, especialmente em dois campos específicos do universo educativo: a educação política e a educação ambiental, ambas vinculadas diretamente ao debate atual sobre democracia e cidadania. Essa nova configuração social está diretamente relacionada às redefinições recentes do campo ambiental, com a transição dos movimentos monossetoriais, baseados na coesão sectária, para as organizações verdes complexas, que construíram um discurso intersubjetivo transnacional e plurissetorial. Tudo isso tecido e amalgamado pela lógica da racionalização cultural weberiana e a epistemologia da complexidade proposta por Edgar Morin.

A educação, nesse cenário, é fundamental como modeladora de valores, concepções, imaginários, seja em sua dimensão política ou ambiental, visto que ambas são voltadas para a cidadania e devem ser encaradas como processos permanentes e continuados de aprendizagem política e social. Afinal, a cidadania tem a ver com a identidade e o pertencimento a uma coletividade. A educação ambiental como formação e exercício de cidadania "refere-se a uma nova forma de encarar a relação do homem com a natureza, baseada numa nova ética, que pressupõe outros valores morais e uma forma diferente de ver o mundo e os homens" (JACOBI, 2003, p. 198). Isso requer um projeto social coletivo, de modo a estimular a participação democrática na formulação de políticas públicas e nos modelos de gestão dos recursos naturais, da biodiversidade, dos espaços urbanos e rurais. Tal projeto exige a consolidação de novos paradigmas educativos. 
Vários autores entendem a educação como a ferramenta social e simbólica para formar e renovar valores, conceitos e ideias, o que, no caso do campo ambiental, possibilita a percepção dos problemas e o desenvolvimento de uma consciência favorável à mudança de atitudes e comportamentos, inclusive no plano concreto do cotidiano (DIAZ, 2002; VARGAS, 2005). Desse ponto de vista, a educação ambiental não deve ser encarada como mais uma disciplina obrigatória nos currículos escolares, com conteúdos formais, provas e outros expedientes próprios do aparato burocrático dos sistemas de ensino. Antes, deve ser concebida como formação e renovação das consciências e das condutas sociais cotidianas. Isso reforça sua abrangência como educação política difusa.

Reigota (2001) e Mota Júnior (2009) destacam o papel político da educação ambiental, com o foco na formação da consciência cidadã e na promoção de condutas e práticas cidadãs. Como se percebe essa concepção de educação ambiental como educação política pressupõe a integração de duas perspectivas, ou seja, aquela calcada na epistemologia e outra na pragmática social. A primeira está relacionada com a matriz das ideias que servem de base filosófica para os conhecimentos acerca da sustentabilidade, tais como holismo, complexidade e ética da responsabilidade. A segunda está ancorada no pressuposto de que o conhecimento ambiental resultante do aprendizado político difuso do cidadão deve ter consequências práticas nos seus comportamentos cotidianos no que se refere ao uso da água, da energia elétrica e em suas demais escolhas de consumo, por exemplo.

No próprio campo da educação ambiental é necessária uma abordagem que reitere a natureza de interdisciplina e de complexidade das temáticas ambientais, uma vez que são vários atores do universo educativo que estão envolvidos, além de diversos sistemas de conhecimentos e de campos de atuação prática. Leff (2002) reforça que a sustentabilidade será viabilizada social e culturalmente apenas se houver sistemas eficientes para mudar os valores e os comportamentos, o que depende de transformações radicais nos sistemas de conhecimento, no ensino formal e na racionalidade que rege as relações sociais, especialmente no campo do consumo. Nessa perspectiva, a educação ambiental (formal ou difusa) poderia funcionar com um antídoto à sociedade do risco, ${ }^{4}$ de modo a continuar promovendo a racionalização cultural nos termos weberianos expostos anteriormente.

4 Termo cunhado por Ulrick Beck para designar uma etapa da modernidade ou uma "segunda modernidade" que emerge da globalização e tem como consequências uma cadeia interrelacionada de riscos sociais, econômicos, políticos e ambientais, que se expressam no consumismo, individualismo, miséria, fome, violência e desastres nucleares, químicos e genéticos (JACOBI, 2003). 


\section{REFERÊNCIAS}

ALEXANDRE, A. F., 2000, A perda da radicalidade do movimento ambientalista. Florianópolis, Editora da Universidade Federal de Santa Catarina, 2000.

ALONSO, Â.; COSTA, V.. Por uma Sociologia dos Conflitos Ambientais no Brasil. Paper apresentado no Encontro do Grupo Meio Ambiente e Desenvolvimento do Conselho Latinoamericando de Ciencias Sociais (Clacso), Rio de Janeiro, 22 e 23 de novembro de 2000.

ARENDT, H. Entre o passado e o futuro. São Paulo: Perspectiva, 2000.

BARBANTI JÚNIOR, O.. Conflitos socioambientais: teorias e práticas. Curitiba. 2006. 257f. Tese de Doutorado, 2006. Programa de Pós-Graduação em Economia. Universidade Federal do Paraná, Curitiba, 2006.

BARROS, F. L. de. Ambientalismo, globalização e novos atores sociais. Sociedade e Estado. Brasília, Universidade de Brasília, v.21, n.1, p.121-137, jan./jun. 1996.

BARROS, A. T. de; SOUSA, J. P.. Jornalismo e ambiente: análise de investigações realizadas no Brasil e em Portugal. Porto: Edições Fernando pessoa, 2010.

BAUMAN, Z.. Modernidade líquida. Rio de Janeiro: Zahar, 2001.

BENJAMIN, C.. Diálogo sobre ecologia, ciência e política. Rio de Janeiro: Nova Fronteira,1983.

BOBBIO, N.. A era dos direitos. Rio de Janeiro: Campus, 1992.

BOTKIN, D.. Qual ecologia para o século XXI? In: BARRÈRE, Martine (Org.). Terra, patrimônio comum: a ciência a serviço do meio ambiente e do desenvolvimento. São Paulo: Nobel, 1992, p.15-26.

CARDOSO, L. A.. O conceito de racionalização no pensamento de Max Weber: entre a ambiguidade e dualidade. Teoria e Debate, Belo Horizonte, Universidade Federal de Minas Gerais, v.16, n.1, jan./jun., 2008, p. 256-275

CARVALHO, I. C.. Educação, meio ambiente e ação política. In: ASCELRAD, Henri. (Org) Meio ambiente e democracia. Rio de Janeiro: Ibase, 1992, p. 32-42.

CASTRO, M. F. de. Democracia, ética e prática judicial no mundo contemporâneo: uma abordagem weberiana. In: SOUSA, Jessé (Org). A atualidade de Max Weber. Brasília: Editora da Universidade de Brasília, 2000, p. 197-233.

DIAZ, Alberto Prado. Educação ambiental como projeto. Porto Alegre: Artmed, 2002.

DOMINGUES, J. M.. A cidade: racionalização e liberdade em Max weber. In: SOUSA, Jessé (Org). A atualidade de Max Weber. Brasília: Editora da Universidade de Brasília, p. 209-234. 
ECO, U.. Cinco escritos morais. São Paulo: Record, 2010.

FIGUEIREDO, V.. Globalização, meio ambiente e novos atores sociais. Sociedade e Estado, Brasília, Universidade de Brasília, v.21, n.1, jan./jun., 1996, p.119-120.

GUATARI, F.. As três ecologias. Campinas: Papirus, 1993.

HOBSBAWN, E.. A era dos extremos. São Paulo: Companhia das Letras, 1995.

JACOBI, P.. Educação ambiental, cidadania e sustentabilidade. Cadernos de Pesquisa, São Paulo, Fundação Carlos Chagas, s/v, n.118, março, 2003, p.189-205.

LEFF, E. Epistemologia ambiental. São Paulo: Cortez, 2002.

LEFF, E, Complexidade, racionalidade ambiental e diálogo de saberes. Educação \& Realidade, Porto Alegre, Universidade Federal do Rio Grande do Sul, v. 34, n. 3, set./dez., 2009, p.17-24.

LEIS, H. R.. A modernidade insustentável: as críticas do ambientalismo à sociedade contemporânea. Petrópolis: Vozes; Florianópolis: Editora da Universidade Federal de Santa Catarina, 1999.

LIPSET, S. M. Consenso e conflito. Gradiva: Lisboa,1985.

MOTA JÚNIOR, V. D. da. Educação ambiental, política, cidadania e consumo. Interacções, Santarém, Escola Superior de Educação de Santarém, v.5, n.11, 2009, p.214-229.

MORIN, E.. Le paradigme perdu: la nature humaine. Paris: Éditions du Seuil, 1973.

MORIN, E. La méthode: les idées. Paris: Éditions Seuil. v.4., 1991a.

MORIN, E.. La pensée écologisée. In: MORIN, Edgar et al. Un nouveau commencement. Paris: Éditions du Seuil, pp.179-193, 1991b.

MORIN, E.. Introducción al pensamiento complejo. Barcelona: Gedisa, 1994.

MORIN, E.. Os sete saberes necessários à educação do futuro. São Paulo: Cortez, 2002.

PÁDUA, J. A.. Natureza e projeto nacional: as origens da ecologia política no Brasil. Rio de Janeiro: Instituto Universitário do Rio de Janeiro, 1996.

PETITAT, A.. Educação difusa e relação social. Educação \& Realidade, Porto Alegre, Universidade Federal do Rio Grande do Sul, v. 36, n. 2, maio/ago., 2011, p.365-376.

PIERUCCI, A. F.. Secularização segundo Max Weber: da contemporânea serventia de voltarmos a acessar um velho sentido. In: SOUZA, Jessé (Org). A atualidade de Max Weber. Brasília: Editora da Universidade de Brasília, 2000, p.105-162.

REIGOTA, M.. O que é educação ambiental. São Paulo: Brasiliense, 2001. 
SCHERER-WARREN, I.. Novos atores e práticas políticas ambientalistas na era da globalização. Sociedade e Estado. Brasília, Universidade de Brasília, v.21, n.1, p.139-48, jan./ jun., 1996.

SCHLUTCHER, W.. Politeísmo de valores: In: SOUSA, Jessé (Org). A atualidade de Max Weber. Brasília: Editora da Universidade de Brasília, 2000a, p.13-48.

SCHLUTCHER, W.. Neutralidade de valor e a ética da responsabilidade. COELHO, Maria F. Pinheiro et al. (Org). Política, ciência e cultura em Weber. Brasília: Editora da Universidade de Brasília, 2000b, p.55-110.

SOARES, L. E.. A racionalidade do "politicamente correto" ou: Weber errou porque estava certo. In: SOUSA, J. (Org). A atualidade de Max Weber. Brasília: Editora da Universidade de Brasília, 2000.

SOEFFNER, H-G.. A crítica da razão sociológica. Civitas, Porto Alegre, v.9, n.2, p. 324-334, maio/ago., 2009.

SOUSA, J.. A ética protestante e a ideologia do atraso brasileiro. In: SOUSA, Jessé (Org). O malandro e o protestante: a tese weberiana e a singularidade cultural brasileira. Brasília: Editora da Universidade de Brasília, 1999, p.17-54.

SOUSA, J.. Acerca do lugar da moralidade na política: Weber, Habermas e a singularidade cultural alemã. In: SOUSA, Jessé. (Org). A atualidade de Max Weber. Brasília: Editora da Universidade de Brasília, p.49-90.

SOUZA, N. M.. Educação ambiental: dilemas da prática contemporânea. Rio de Janeiro: Editora da Universidade Estácio de Sá, 2000.

STROH, P. Y.. Fitzcarraldo e a Agenda 21: desafios da sustentabilidade amazônica.1998. 223f. Tese de doutoramento em Sociologia. Programa de PósGraduação em Sociologia. Universidade de Brasília. Brasília, 1998.

VIEIRA, P. F. Meio ambiente, desenvolvimento e planejamento. In: VIOLA, Eduardo et al. Meio ambiente, desenvolvimento e cidadania: desafios para as ciências sociais. São Paulo: Cortez, 1995, p.45-98.

VIOLA, E.; LEIS, H. O ambientalismo multissetorial no Brasil para além da Rio92: o desafio de uma estratégia globalista viável. In: VIOLA, Eduardo et al. (Org). Meio ambiente desenvolvimento e cidadania: desafios para as ciências sociais. São Paulo: Cortez, 1995, p.134-160.

VARGAS, L. A.. Educação ambiental: a base para uma ação político/transformadora na sociedade. Revista Eletrônica do Mestrado em Educação Ambiental, Natal, v.15, n.2, jul./dez., 2005, p.72-79.

WEBER, M.. A ética protestante e o espírito do capitalismo. São Paulo: Pioneira, 1989.

Texto submetido à Revista em 29.12.2015 Aceito para publicação em 13.01.2017 